\title{
Neural correlates of working memory training in HIV patients: study protocol for a randomized controlled trial
}

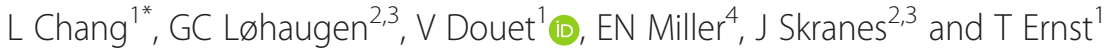

\begin{abstract}
Background: Potent combined antiretroviral therapy decreased the incidence and severity of HIV-associated neurocognitive disorders (HAND); however, no specific effective pharmacotherapy exists for HAND. Patients with HIV commonly have deficits in working memory and attention, which may negatively impact many other cognitive domains, leading to HAND. Since HAND may lead to loss of independence in activities of daily living and negative emotional well-being, and incur a high economic burden, effective treatments for HAND are urgently needed. This study aims to determine whether adaptive working memory training might improve cognitive functions and neural network efficiency and possibly decrease neuroinflammation. This study also aims to assess whether subjects with the LMX1A-rs4657412 TT(AA) genotype show greater training effects from working memory training than TC(AG) or CC(GG)-carriers.

Methods/Design: 60 HIV-infected and 60 seronegative control participants will be randomized to a double-blind active-controlled study, using adaptive versus non-adaptive Cogmed Working Memory Training ${ }^{\circledast}$ (CWMT), 20-25 sessions over 5-8 weeks. Each subject will be assessed with near- and far-transfer cognitive tasks, self-reported mood and executive function questionnaires, and blood-oxygenation level-dependent functional MRI during working memory ( $n$-back) and visual attention (ball tracking) tasks, at baseline, 1-month, and 6-months after CWMT. Furthermore, genotyping for LMX1A-rs4657412 will be performed to identify whether subjects with the T(AA)genotype show greater gain or neural efficiency after CWMT than those with other genotypes. Lastly, cerebrospinal fluid will be obtained before and after CWMT to explore changes in levels of inflammatory proteins (cytokines and chemokines) and monoamines.

Discussion: Improving working memory in HIV patients, using CWMT, might slow the progression or delay the onset of HAND. Observation of decreased brain activation or normalized neural networks, using fMRI, after CWMT would lead to a better understanding of how neural networks are modulated by CWMT. Moreover, validating the greater training gain in subjects with the LMXIA-TT(AA) genotype could lead to a personalized approach for future working memory training studies. Demonstrating and understanding the neural correlates of the efficacy of CWMT in HIV patients could lead to a safe adjunctive therapy for HAND, and possibly other brain disorders.
\end{abstract}

Trial registration: ClinicalTrial.gov, NCT02602418.

Keywords: Cogmed ${ }^{\oplus}$, Computerized training, fMRI, HIV, Working memory

\footnotetext{
* Correspondence: Ichang@hawaii.edu

1Department of Medicine, John A. Burns School of Medicine, The Queen's

Medical Center, University of Hawaii at Manoa, 1356 Lusitana Street, 7th

Floor UH Tower, Honolulu, HI, USA

Full list of author information is available at the end of the article
} 


\section{Background}

The incidence of HIV-associated dementia has declined dramatically since the introduction of potent combined antiretroviral therapy; however, milder forms of HIVassociated neurocognitive disorders (HAND) persist. Some 30 to $50 \%$ of HIV-infected individuals have HAND, which is more prevalent in those older than 50 years $[1,2]$. Other co-morbidities, such as substance abuse (e.g., alcohol, cannabis, or psychostimulants) and hepatitis $\mathrm{C}$ infection, further exacerbate or hasten the development of HAND, partly owing to poorer medication adherence compared with those without HAND $[3,4]$. With an increasing proportion of HIV-infected individuals at risk of HAND, which leads to both functional and occupational disabilities, the development of effective treatments or adjunctive therapy for these patients is critical.

The current therapy for HIV infection leaves a 'therapeutic gap' for HAND [1, 2]. Combined antiretroviral therapy is effective at suppressing the viral burden but cannot reverse HAND completely or prevent the development of HAND, even in those with long-standing aviremia [5]. In addition, antiretroviral drugs may have adverse or neurotoxic effects on the brain [6-8]. A number of pharmacological trials, including trials of minocycline [9], CEP-1347 [10], memantine [11], lithium [12], peptide $\mathrm{T}$ [13], and selegiline [14-16], were conducted with no clear efficacy for cognitive improvements, although some of these studies demonstrated positive effects on neuroimaging measures in human beings or immunohistochemistry in animal models. Therefore, no evidence-based treatment is available to improve the cognitive function of patients with HAND. In addition, neuropathological, neuroimaging, and cerebrospinal fluid studies consistently showed ongoing aberrant neuroinflammation, with persistent glial activation [17], and lesser dopamine transporters $[18,19]$; both may contribute to brain injury and HAND in HIV patients. Hence, effective treatment for HAND might require a multimodal approach.

Another important reason to develop an effective treatment is that HAND leads to higher healthcare costs. For instance, a study of patients with HIV or AIDS in a community-based clinic in Canada found that the care for those with a neuropsychiatric disorder was more costly, both immediately before and after the diagnosis, regardless of the specific neuropsychiatric diagnosis [20]. Likewise, an Australian study showed that with the predicted doubling of HIV infection in men and tripling in women over the next two decades, the cost of care could nearly double at the current $7 \%$ prevalence of HIVassociated dementia, primarily for residential care [21]. Another study from Sweden on the pharmacoeconomics of mild cognitive impairment showed that postponing the development of dementia even for a few years after diagnosis of mild cognitive impairment would result in cost savings of approximately $\$ 5,300$ per person [22]. Therefore, an effective treatment for HAND or to delay the onset of HAND, even in a subset of HIV-infected individuals, might lead to significant cost savings.

The major cognitive domains affected in HAND are attention and working memory [23, 24], in both visual and verbal domains [25-28]. Working memory is defined as the cognitive skill to retain and manipulate information 'online' over short periods of time. Working memory is thus necessary for concentration and maintaining awareness and is crucial for learning and executive functions, such as reasoning and planning. Working memory is also needed in daily life in all settings. Hence, deficits in working memory may negatively affect many other cognitive domains. While the introduction of combined antiretroviral therapy led to generally improved neuropsychological function, working memory dysfunction was not improved or was even exacerbated with ongoing infection $[1,29]$. Working memory dysfunction in HIV has major consequences, such as being a strong predictor of unemployment and dependence in activities of daily living [30], self-reported cognitive complaints [31], and poorer medication adherence [32, 33]. Therefore, enhancing working memory ability and delaying progression of working memory decline should benefit HIV-infected individuals.

Importantly, working memory skills can be trained, for instance, using Cogmed Working Memory Training (CWMT), a computer-based adaptive working memory training program that is effective for improving cognition. The efficacy of CWMT was first demonstrated in children with attention deficit hyperactivity disorders [34], who showed better non-verbal and verbal working memory performance and improved response inhibition and reasoning, as well as reduced parent-rated inattentive symptoms of attention deficit hyperactivity disorders [35]. Patients with traumatic brain injury also had improved functioning in daily life activities, which was maintained even 6 months after CWMT [36]. Other populations who benefitted from CWMT included stroke victims [37], adolescents born preterm with extremely low birth weight [38], children with cochlear implants [39], and healthy older persons [40]. However, this remarkably safe and innovative intervention has not been evaluated as an adjunctive therapy for HAND.

To our knowledge, no study has investigated the neural correlates of working memory training in HIV patients, or whether neural networks might re-organize or show corresponding improved neural efficiency. Working memory deficits in HIV patients probably involve injuries to the frontostriatal circuits, which are brain regions that have been shown in neuropathological 
studies [41] to be preferentially affected in HIV patients. Working memory deficits have been observed in encoding [23], reaction times [42], and simultaneous shortterm storage and processing [43], suggesting subcortical deficits as well as abnormalities of the prefrontal cortex [26]. The brain is highly 'plastic' in that brain activities and network connections can change quickly and that changes can last for a long time after a task is practiced, as found in tasks involving visual attention [44], object naming [45], motor learning [46, 47], and working memory [48-50]. Blood-oxygenation level-dependent functional magnetic resonance imaging (BOLD-fMRI) studies following 5-weeks of adaptive CWMT showed increased training-related activity in the medial frontal gyrus and parietal cortices for the trained tasks [51, 52] and in the the inferior frontal gyrus for the untrained tasks with varied working memory load [52]. However, compared with fixed low-level training (active control condition), older adults who received adaptive working memory training showed decreased brain activation in frontal, parietal, and temporal cortices but increased activity in the caudate and thalamus [53]. Transfer of performance improvement (gain) to untrained tasks (transfer of gain) requires overlapping networks and brain regions common to both tasks, especially the striatum [54]. Our proposed fMRI studies will further assess brain changes associated with improvements on working memory and other cognitive tasks.

Recent data also indicate that individuals with different genotypes for dopamine-related genes may have different training gain, such as polymorphisms in $L M X 1 \mathrm{~A}$ [55] and catechol-O-methyltransferase Val158Met [56]. This study will focus on $L M X 1 A$, which encodes for the protein LIM homeobox transcription factor 1 alpha, a positive regulator of insulin gene transcription, but is also involved in the proliferation, differentiation, and maintenance of dopamine-producing neurons in the midbrain [57-59]. Polymorphisms in LMX1A were associated with dopaminergic disorders, such as Parkinson's disease [60] and schizophrenia [61], and, recently, with the effects of working memory training [55]. Specifically, subjects with TT(AA) alleles at the LMX1A-rs4657412 had greater training-related gains in verbal working memory than those with heterozygous TC(AG) or CC(GG) alleles [55]. Since HIV patients commonly showed dopaminergic deficits, with decreased dopamine transporters [18, 19] and decreased cerebrospinal fluid dopamine and dopamine metabolites [62], we will explore whether genetic variations of $L M X 1 A$-rs4657412 modulates working memory training effects and cerebrospinal fluid monoamines and their metabolites in our subjects.

Based on this prior knowledge, the current study has three major aims and one exploratory aim.
- Aim 1: To perform a double-blind active-controlled study on the effectiveness of CWMT (25 sessions over 5-8 weeks) in HIV-infected and seronegative subjects, with or without cognitive deficits, and assess whether the training will improve cognitive functioning (on working memory and some non-trained tasks that require working memory) at 1 month (to assess gain) and 6 months (to assess maintenance of gain) after the training.

- Aim 2: To assess the neural correlates of working memory training, and determine whether brain activation will improve, at 1 month and 6 -months after the training, as assessed by functional MRI (fMRI) during working memory and attention tasks.

- Aim 3: Since individuals with the TT(AA) genotype for the single nucleotide polymorphism LMX1Ars4657412 had greater magnitude of training-related gains in verbal working memory [55], we will assess our subjects for the allelic variations on training results (gain and maintenance).

\section{Exploratory aim}

We will explore changes in neuroinflammatory markers, and monoamine and their metabolites in the cerebrospinal fluid before and at least 1 month after CWMT, and evaluate the relationships between cerebrospinal fluid markers, cognitive performance, and BOLD-fMRI signals.

\section{Methods/design}

The proposed study uses a $2 \times 2$ repeated-measures analysis of covariance (ANCOVA) design to evaluate the effects of 5 weeks of CWMT, adaptive versus active control (fixed low level)' training, as assessed by the improvement index (generated from task performances within the CWMT), neurocognitive testing, BOLD-fMRI measurements, cerebrospinal fluid neuroinflammatory proteins, monoamine, and metabolite levels. We propose to enroll $60 \mathrm{HIV}$-infected individuals and 60 seronegative healthy participants, with 30 adaptive and 30 activecontrol-training subjects randomized in each group (Fig. 1). HIV-positive and seronegative subject groups will be matched by age, sex, education, socioeconomic status, and cognitive status (matched by global cognitive score from the seven cognitive domains tested), as well as other co-variates (e.g., nicotine smoking and other substances abused). Based on the initial screening evaluations, subjects who fulfill all study criteria will be scheduled for a baseline neuropsychological evaluation, MRI-fMRI scans, and a lumbar puncture.

\section{Primary and secondary outcome measures}

The main goal of this study is to examine the effectiveness of intensive adaptive working memory training for 


\section{Study Design (Double-Blind Active-Controlled)}

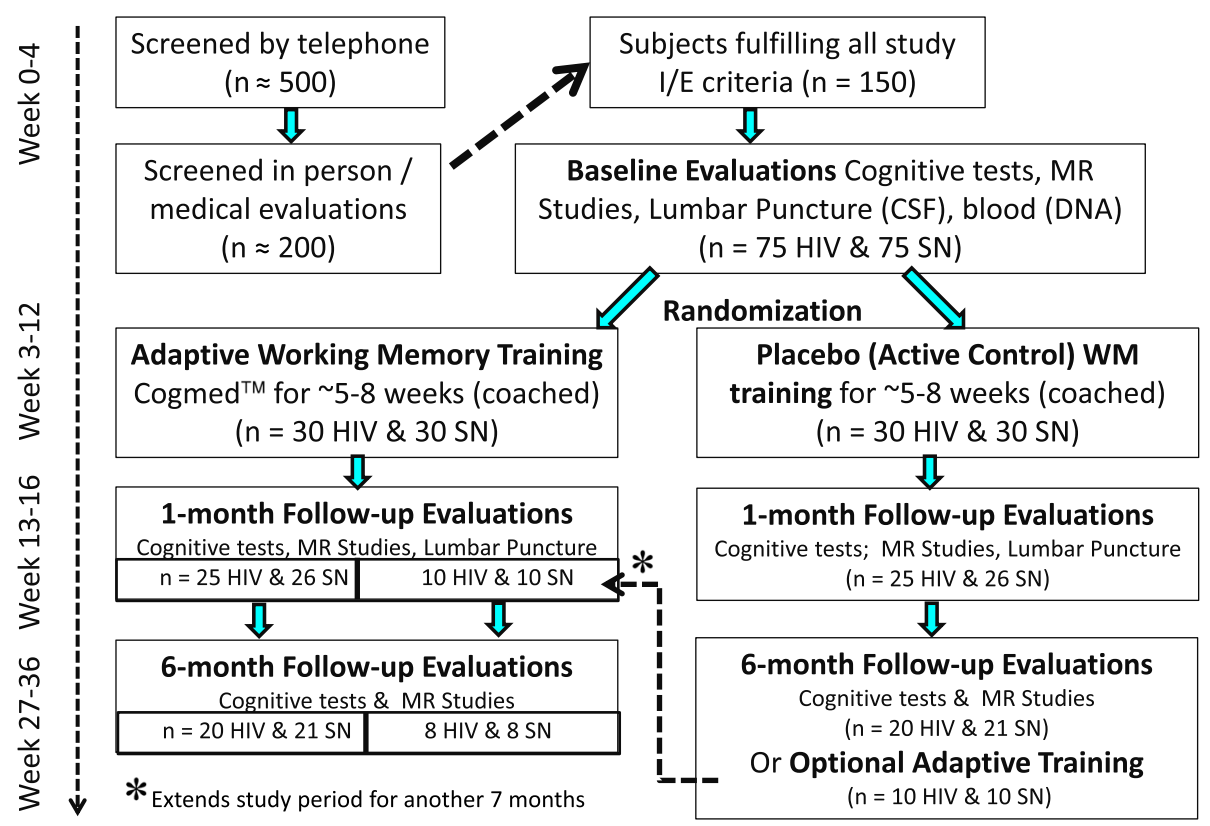

Fig. 1 Study design. We plan to screen $\approx 500$ individuals initially by telephone and 200 of these potentially eligible participants in person, to identify $\approx 150$ subjects who will fulfill our study criteria, and complete the baseline evaluation. We expect that only $\approx 120$ (60 HIV and 60 seronegative) will follow through and be randomized for the training. We also expect that only $85 \%(n=102,50 \mathrm{HIV}$, and 52 seronegative) will return for the 1 month follow-up and only $80 \%$ of these ( $n=86,40 \mathrm{HIV}$, and 42 seronegative) will return to complete the 6-month follow-up evaluations. Furthermore, we expect that $\approx 20$ participants who completed the 'active control' training will want to continue with the 'adaptive training'. CSF, cerebrospinal fluid; I/E, inclusion or exclusion; MR, magnetic resonance; SN, seronegative; WM, working memory.

the treatment of HAND. The primary outcome measures will be the improvement index on CWMT, improvement on non-trained near-transfer working memory tasks, and changes on brain activation assessed with BOLD-fMRI during working memory and attention tasks. Secondary contrasts will evaluate genotype effects (LMX1A, TT(AA) versus TC(AG) or CC(GG)) on cognitive improvements and BOLD-fMRI. We will also assess CWMT-related improvements on self-reported depressive and various psychopathological symptoms, using the Center for Epidemiological Studies-Depression Scale Revised and Symptom Checklist-90 revised items, and on self-rated functionality, using the Independent Activity of Daily Living assessment and the Behavior Rating Inventory of Executive Function-Adult Version.

\section{Participants}

Subjects will be recruited via flyers, referrals from local HIV clinics, by word of mouth, or from ongoing studies. Potential research subjects will be screened by telephone or on-site, before being scheduled for a detailed outpatient evaluation at the UH-QMC MR Research Center at the Queen's Medical Center in Honolulu, Hawaii.

In our pilot studies, we observed effect sizes from 0.7 to 1.2 for pre versus post CWMT in HIV-positive subjects in four of the working memory tests. We will need to enroll $\approx 17$ HIV-positive subjects to detect an effect size of 0.7 for $80 \%$ power (two-sided test). Effect sizes for BOLD signal change (pre versus post adaptive CWMT (0 and 1back)) were 0.58-1.5 in the pilot HIV-positive subjects; at least 26 HIV-positive subjects are needed to detect an effect size of 0.58 for $80 \%$ power (two-sided test). Since we encountered an $\approx 15 \%$ (13\% in HIV and $20 \%$ in the seronegative group) attrition rate in our pilot study, we propose to enroll $30 \mathrm{HIV}$ and 30 seronegative subjects per training group to ensure adequate power, for a total of 120 subjects (60 HIV, 60 seronegative). Based on our experience, we will have to screen $\approx 500$ individuals initially by telephone and 200 of these potentially eligible participants in person to have $\approx 150$ subjects who will fulfill our study criteria, and complete the baseline evaluation. We expect that only $\approx 120$ subjects ( 60 HIV and 60 seronegative) will follow through and be randomized for the training. We also expect that only $85 \%(n=102,50 \mathrm{HIV}$ and 52 seronegative) will return for the 1 month follow-up and only $80 \%$ of these ( $n=86,40 \mathrm{HIV}$ and 42 seronegative) will return to complete the 6-month follow-up evaluations. Furthermore, we expect that $\approx 20$ participants who completed the 'active control' training will want to continue with the 'adaptive training' (Fig. 1). 
HIV-infected participants must meet the following inclusion criteria: (1) men or women of any ethnicity, ages $\geq 18$ years and able to provide informed consent; (2) HIV seropositive (with documentation from medical records); (3) stable on an antiretroviral regimen for 6 months or will remain without antiretroviral treatment during the duration of the CWMT study.

Seronegative healthy participants must meet the following inclusion criteria: (1) men or women of any ethnicity, ages $\geq 18$ years and able to give informed consent; (2) seronegative for HIV (to be confirmed by an HIV ELISA blood test if screened positive with ClearView ${ }^{\oplus}$ COMPLETE HIV-1/2 test).

Exclusion criteria for all subjects are: (1) history of comorbid psychiatric illness that might confound the analysis of the study (e.g., schizophrenia, obsessivecompulsive disorder, major depression, or bipolar disorder); (2) confounding neurological disorder (e.g., multiple sclerosis, Parkinson's disease, non-HIV brain infections, neoplasms, cerebral palsy, or significant head trauma with loss of consciousness $>30$ minutes); (3) significantly abnormal screening laboratory tests ( $>2$ standard deviations) that might indicate a chronic medical condition (e.g., diabetes, severe cardiac, renal or liver disorders) that might affect brain function; (4) medications that could significantly alter functional brain imaging studies; (5) current or history of drug dependence within the previous 2 years, including amphetamines, cocaine, alcohol, and opiates, according to DSM-V dependency criteria (past casual or recreational usage will not be excluded); (6) positive urine toxicology screen (methamphetamine, amphetamine, cocaine, marijuana, benzodiazepine, barbiturates, and opiates except for false positive tests due to medications) on day of neuropsychological testing or fMRI studies; (7) pregnancy (to be verified by urine pregnancy test in women of childbearing age); (8) inability to read at an 8th-grade level (to be verified by the Wechsler Test of Adult Reading); (9) other contraindications for MRI studies, such as metallic or electronic implants in the body (e.g., pacemaker, surgical clips, or pumps), or severe claustrophobia.

\section{Baseline assessments}

We will first explain the study to each subject and obtain oral and written consent. The study design, experiments, and consent forms were approved by the institutional review board of the University of Hawaii at Manoa (CHS\#20523). A detailed medical and drug use history and physical and neuropsychiatric evaluations will be performed, along with screening blood tests to assess general health, including complete blood cell count, chemistry panel, thyroid function tests, hepatitis $C$ and HIV serology. An electrocardiogram will be obtained to screen for significant cardiac abnormalities; subjects will be referred for further cardiac evaluations should significant abnormalities be found. Psychiatric and quality-oflife evaluations will be additionally performed through a battery of questionnaires and self-reported assessments; some will be repeated after training (Table 1).

Subjects with significant psychiatric symptoms will be further assessed by a qualified physician, to determine whether psychiatric referral is necessary. Those with suicidal thoughts or acute intoxication will be sent to the psychiatric emergency department. Subjects with significant medical problems, screening blood test abnormalities, or electrocardiographic abnormalities will be referred to their primary care physicians, other clinics or the emergency department as needed.

\section{Neuropsychological evaluation}

The 2 hour long neuropsychological test battery is designed to detect deficits in (1) working memory and attention, which implicate networks in frontal and parietal regions; (2) decision making and inhibition, which involve primarily the anterior cingulate and orbitofrontal cortices; and (3) motor and psychomotor speed, which are associated with alterations in the basal ganglia and cerebellum.

1. Diagnosis of HAND or HAND-equivalent at baseline will be determined using z-scores from seven cognitive domains, adjusted for age and education, and derived from our existing normative database (including $\approx 450$ healthy seronegative controls tested with the same protocol). HAND classification will be made according to the Updated Research Nosology for HAND [63] by physicians for all subjects. The HIV-positive and seronegative control groups will be matched by their cognitive status (i.e., global z-score) (Table 2).

2. General intelligence: the Wechsler Test of Adult Reading will provide an estimate of premorbid intellectual functioning during our screening procedure to ensure that the subjects have a verbal intelligence quotient $>80$ and can provide consent. The Wechsler Adult Intelligence Scale IV will be used to evaluate general cognitive ability (intelligence quotient) for all subjects at baseline.

3. Assessments of changes in working memory, other cognition and function (primary outcomes) will be administered repeatedly at baseline, 1 month after training (either adaptive working memory or 'active control' training condition), and 6 months after the adaptive working memory training. Alternative word lists or stories will be used for repeated testing. Table 2 shows the tests involved in the trained working memory tests, which will include the 'start index, maximum index, and improvement index', the 
Table 1 Questionnaires and interviews

\begin{tabular}{|c|c|c|c|c|}
\hline & Outcome measures & Baseline & $\begin{array}{l}1 \text { month after } \\
\text { training }\end{array}$ & $\begin{array}{l}6 \text { months after } \\
\text { training }\end{array}$ \\
\hline Hollingshead Four Factor Index [90] & $\begin{array}{l}\text { Socioeconomic status; combination of race, ethnicity, } \\
\text { occupational status and education level }\end{array}$ & $\checkmark$ & & \\
\hline \multicolumn{5}{|l|}{ Psychiatric assessments } \\
\hline Symptom Checklist-90-revised & Psychological and emotional distress & $\checkmark$ & $\checkmark$ & $\checkmark$ \\
\hline $\begin{array}{l}\text { Center for Epidemiological Studies- } \\
\text { Depression Scale [91] }\end{array}$ & $\begin{array}{l}\text { Depressive symptoms and to rule out possible } \\
\text { major depression }\end{array}$ & $\checkmark$ & $\checkmark$ & $\checkmark$ \\
\hline \multicolumn{5}{|l|}{ Substance use assessments } \\
\hline $\begin{array}{l}\text { Substance Abuse Subtle Screening } \\
\text { Inventory-3 [92] }\end{array}$ & $\begin{array}{l}\text { Identification of individuals with a high probability } \\
\text { of having a substance use disorder }\end{array}$ & $\checkmark$ & $\checkmark$ & $\checkmark$ \\
\hline Urine toxicology & Substance usage & $\checkmark$ & $\checkmark$ & $\checkmark$ \\
\hline \multicolumn{5}{|l|}{ Quality-of-life assessments } \\
\hline Independent Activity of Daily Living [93] & Ability to carry out daily functions & $\checkmark$ & $\checkmark$ & $\checkmark$ \\
\hline $\begin{array}{l}\text { Behavior Rating Inventory of Executive } \\
\text { Function-Adult Version }\end{array}$ & Executive function & $\checkmark$ & $\checkmark$ & $\checkmark$ \\
\hline $\begin{array}{l}\text { Pittsburgh Sleep Quality Index [94], Epworth } \\
\text { Sleepiness Scale [95] }\end{array}$ & General level of daytime sleepiness & $\checkmark$ & $\checkmark$ & $\checkmark$ \\
\hline $\mathrm{PROMIS}^{\oplus}$ & $\begin{array}{l}\text { Global health status and pain intensity, interference } \\
\text { and behavior }\end{array}$ & $\checkmark$ & $\checkmark$ & $\checkmark$ \\
\hline Medical Outcomes Study HIV Health Survey [96] & Health status for HIV-positive patients & $\checkmark$ & $\checkmark$ & $\checkmark$ \\
\hline World Health Organization Quality of Life [97] & Well-being and quality of life & $\checkmark$ & $\checkmark$ & $\checkmark$ \\
\hline \multicolumn{5}{|l|}{ Biospecimens } \\
\hline Blood & DNA and genotyping & $\checkmark$ & & \\
\hline Blood and serum & $\begin{array}{l}\text { Cytokines and monoamines and neurometabolite } \\
\text { measurements }\end{array}$ & $\checkmark$ & $\checkmark$ & $\checkmark$ \\
\hline Cerebrospinal fluid & $\begin{array}{l}\text { Cytokines monoamines and neurometabolite } \\
\text { measurements }\end{array}$ & $\checkmark$ & $\checkmark$ & \\
\hline
\end{tabular}

non-trained working memory tests and the transfer of working memory capacity gain to other cognitive functions.

For the non-trained working memory tasks, no practice effects are expected [64]. However, for the other neuropsychological tests, variable degrees of practice effects will occur with test-retest [65]; we will control for such practice effects by performing the same tests before and after CWMT in both HIV-positive and seronegative control subjects.

\section{Cognitive intervention using Cogmed $^{\circledR}$ RM}

The Cogmed ${ }^{\circledR}$ RM (Table 3) was developed for schoolaged children; however, we chose this version for our adult participants since it is more colorful and appealing to the participants than the adult version (Cogmed $^{\circledR}$ QM). The training program consists of 25 training sessions (minimum of 20 required), 30-40 minutes per day, 4-5 days per week over a 5-8 week period [35]. Subjects will perform either the 'active control', with a fixed low level across each task, or an 'adaptive' version, with increasing difficulty for the working memory tasks. The training will be performed either in the participants' homes, or at the research laboratory. We will ensure that participants have high-speed internet access. Subjects will be trained using verbal and non-verbal working memory tasks that involve: (1) maintenance of several stimuli at the same time; (2) short delays during which the representation of stimuli should be held in the working memory; (3) unique sequencing of stimulus order in each trial. Training will be supplemented with weekly guidance by trained 'coaches', who can review subjects' progress online and will telephone them to give feedback, motivation, and advice to optimize their training experience.

\section{Participant randomization}

Individuals meeting all study criteria will be randomized, with 30 participants assigned to each training condition to maintain a balanced design. Randomization to study condition will be stratified across characteristics that might affect outcomes. Stratification variables include age, sex (male, female), and severity of cognitive deficits (based on the global cognitive z-score). This random assignment will ensure that both the participant and the 
Table 2 Neuropsychological assessments (non-trained working memory tests)

\begin{tabular}{|c|c|c|c|}
\hline & Baseline & $\begin{array}{l}1 \text { month after } \\
\text { training }\end{array}$ & $\begin{array}{l}6 \text { months after } \\
\text { training }\end{array}$ \\
\hline \multicolumn{4}{|l|}{ Attention, working memory } \\
\hline Paced Auditory Serial Addition Test & $\checkmark$ & & \\
\hline $\begin{array}{l}\text { Wechsler Adult Intelligence Scale IV (Digit Span, Letter } \\
\text { Number Sequencing, Arithmetic, and Digit-Symbol Coding) }\end{array}$ & $\checkmark$ & $\checkmark$ & $\checkmark$ \\
\hline California Computerized Assessment Package & $\checkmark$ & $\checkmark$ & $\checkmark$ \\
\hline Delis-Kaplan Executive Function System & $\checkmark$ & $\checkmark$ & $\checkmark$ \\
\hline \multicolumn{4}{|l|}{ Abstraction, executive functions } \\
\hline Stroop Color Interference Test & $\checkmark$ & & \\
\hline Trail Making Test Part B & $\checkmark$ & & \\
\hline \multicolumn{4}{|l|}{ Fluency } \\
\hline Controlled Oral Word Association Test (FAS) & $\checkmark$ & & \\
\hline Design Fluency Tests (Ruff Figural Fluency) & $\checkmark$ & & \\
\hline \multicolumn{4}{|l|}{ Memory } \\
\hline Rey Auditory Verbal Learning Test Delayed Recall & $\checkmark$ & $\checkmark$ & $\checkmark$ \\
\hline Rey Osterrieth Complex Figure Test & $\checkmark$ & $\checkmark$ & $\checkmark$ \\
\hline \multicolumn{4}{|l|}{ Speed of information processing, psychomotor speed } \\
\hline Symbol Digit Modalities Test & $\checkmark$ & & \\
\hline Trail Making Test Part A & $\checkmark$ & & \\
\hline \multicolumn{4}{|l|}{ Motor skills } \\
\hline Grooved pegboard test (dominant and non-dominant hand) & $\checkmark$ & & \\
\hline \multicolumn{4}{|l|}{ Verbal, language } \\
\hline Wechsler Adult Intelligence Scale, fourth edition, verbal comprehension index & $\checkmark$ & & \\
\hline Wechsler Test of Adult Reading & $\checkmark$ & & \\
\hline Wechsler Adult Intelligence Scale & $\checkmark$ & & \\
\hline \multicolumn{4}{|l|}{ Wechsler Memory Scale IV } \\
\hline Spatial span & $\checkmark$ & $\checkmark$ & $\checkmark$ \\
\hline Visual, verbal immediate and long-term memory & $\checkmark$ & $\checkmark$ & $\checkmark$ \\
\hline Mental control & $\checkmark$ & $\checkmark$ & $\checkmark$ \\
\hline
\end{tabular}

'coaches' (who will monitor the subjects online and by phone) for the training will be blinded to the training being used. No other members of the study team (except for the principal investigator) or participants will be informed of which condition assignment has been made. The randomization assignment will remain blinded until 1 month after the training and the follow-up visit are complete. Subjects who were trained on the active control (low-level training) condition will then be offered the opportunity to be trained on the intensive adaptive working memory training (open-label phase), and will be followed-up again at 1 month and 6 months after the adaptive training. Subjects unable to participate in the open-label phase during this period will be given the option to continue participation after the active control 6month follow-up. The data manager will maintain the records that link specific participant identification numbers to study conditions, and assignment codes. This information will be available for the principal investigator in case there is any need to break the study blind for a specific participant while the individual is still in the study.

\section{MRI}

All participants will undergo a series of MRI sessions before, and 1-month and 6-months after CWMT. All structural and fMRI studies will be performed on a research-dedicated 3 Tesla Siemens TIM Trio scanner (VB17), using a 12-channel phase-array head coil.

\section{Structural MRI}

A 3D magnetization-prepared rapid gradient-echo scan will be performed (sagittal, TE/TR/TI $=4.9 \mathrm{~ms} / 2.2 \mathrm{~s} / 1 \mathrm{~s}$, $7^{\circ}$ flip angle, $1 \mathrm{~mm}$ resolution covering the whole-brain). Next, a 3D-T2-weighted sequence (SPACE) will be acquired (sagittal, TR/TE $=3200 / 447 \mathrm{~ms}$, field of view $=$ 
Table 3 Description of the 12 modules in Cogmed $^{\circledR}$ Working Memory Training

\begin{tabular}{|c|c|}
\hline Task & Description \\
\hline \multicolumn{2}{|c|}{ Verbal working memory (with visuospatial components) } \\
\hline $\begin{array}{l}\text { Input module } \\
\text { (numbers) }\end{array}$ & $\begin{array}{l}\text { A panel with } 1 \text { to } 9 \text { is shown. Numbers are presented aurally and light up on the panel sequentially. } \\
\text { Participants then have to click on the numbers in the reversed sequence. }\end{array}$ \\
\hline $\begin{array}{l}\text { Input module with lid } \\
\text { (hidden numbers) }\end{array}$ & $\begin{array}{l}\text { Same as previous task, except numbers are presented aurally only, since they are covered by a lid, which } \\
\text { opens when all the numbers are read. }\end{array}$ \\
\hline Stabilizer (letters) & $\begin{array}{l}\text { A circle of lamps is shown. A sequence of letters is presented aurally along with specific lamps that light up. Participants } \\
\text { are then presented with a letter in the middle of the circle, and have to click on the lamp that lit up. }\end{array}$ \\
\hline Decoder & $\begin{array}{l}\text { Letters are read sequentially along with a lamp that lights up. The participant then has to reproduce the sequence } \\
\text { by selecting one letter from three possible letters below each lamp. }\end{array}$ \\
\hline \multicolumn{2}{|l|}{ Visuospatial working memory } \\
\hline Visual data link (grid) & $\begin{array}{l}\text { Lamps light up sequentially in a } 4 \times 4 \text { grid, and the participant must reproduce the sequence by clicking on the lamps } \\
\text { in the same order afterwards. }\end{array}$ \\
\hline $\begin{array}{l}\text { Rotating data link } \\
\text { (rotating grid) }\end{array}$ & $\begin{array}{l}\text { Same as the grid task above, except that after the lamps light up, the entire board rotates } 90^{\circ} \text { and the participant has } \\
\text { to click on the sequence of lamps in the rotated grid. }\end{array}$ \\
\hline $\begin{array}{l}\text { Data room } \\
\text { (three-dimensional grid) }\end{array}$ & $\begin{array}{l}\text { Lamps will light up sequentially in a three-dimensional box (view from the front), with four lamps per plane, and the } \\
\text { participant must reproduce the sequence by clicking on the lamps. }\end{array}$ \\
\hline $\begin{array}{l}\text { Three-dimensional } \\
\text { cube }\end{array}$ & $\begin{array}{l}\text { The program zooms in on different planes of a cube (four squares on the back and two squares on the other planes) } \\
\text { as they light up sequentially. The participant must click the squares in the correct order. }\end{array}$ \\
\hline Rotating (rotating dot) & $\begin{array}{l}\text { Lamps light up sequentially on a circle, which rotates slowly clockwise, and the participant has to reproduce the } \\
\text { sequence by clicking on the lamps on the moving circle. }\end{array}$ \\
\hline Sorter & Boxes open to reveal numbers out of order and the participant must click on the boxes in the correct numerical order. \\
\hline Asteroids & $\begin{array}{l}\text { Asteroids light up sequentially while moving around the screen and the participant must reproduce the sequence by } \\
\text { clicking on the moving asteroids. }\end{array}$ \\
\hline Space whack & $\begin{array}{l}\text { Craters emit puffs of smoke sequentially. The participant must remember the order that the puffs appeared, in order } \\
\text { to click on the alien that will pop out of the crater in the same sequence. }\end{array}$ \\
\hline
\end{tabular}

$320 \mathrm{~mm}, 1.0 \times 1.0 \times 1.0 \mathrm{~mm}$ resolution, 192 slices, generalized autocalibrating partially parallel acquisitions $($ GRAPPA $)=2,3: 52 \mathrm{~min})$. Both scans will be reviewed to screen for possible brain lesions or structural abnormalities.

\section{BOLD-fMRI}

The entire brain is scanned continuously with an axial single-shot gradient-echo echo planar imaging sequence (TE/TR30/2500 ms, $20 \mathrm{~cm}$ field of view, $64 \times 64$ resolution, $\approx 35 \times 3 \mathrm{~mm}$ slices, no gap) with motion correction. An electronic pulse from the scanner synchronizes the fMRI scan and stimulus presentation. Scans with excess motion (more than $\pm 1 \mathrm{~mm}$ translations or $\pm 1^{\circ}$ rotations) are repeated immediately.

\section{fMRI paradigms}

Each subject will perform six different tasks during the fMRI scans. Tasks will be displayed using a binocular video display (Nordic Neurolab Inc. ${ }^{\mathrm{Im}}$ ). Subjects will be trained first outside the scanner to ensure that they will be able to perform the tasks well during the scans (>80\% accuracy, monitored during the scan). Scans with unacceptable response accuracy will be repeated immediately.

\section{Working memory (n-back)}

This task uses a block design (30 s of alternating control and activation periods, including $3 \mathrm{~s}$ of instruction). During activation periods, a random sequence of single letters is presented (1 letter per second for $500 \mathrm{~ms}$ ). Subjects are trained to press a button whenever the current letter is identical to the letter 1 or 2 events back, or for any number (0-back). The targets (i.e., 0-, 1-, or 2-back events) are random events (5/30 s block). Button events are used to determine accuracy and reaction times. During control periods, subjects passively view a random sequence of symbols (non-letters), with matching font size, brightness, and timing.

\section{Visual attention (ball tracking)}

These tasks evaluate non-verbal visual attention [66, 67], which we also expect to improve after working memory training. Subjects mentally track two, three, or four target balls that are highlighted briefly among 10 randomly moving, colliding balls. Every $12.5 \mathrm{~s}$, another set of balls is highlighted for $1 \mathrm{~s}$ and the subjects push a button if subjects agreed that the balls were the original targets (performance monitoring). Periods of tracking (1 min) alternate with passive viewing $(1 \mathrm{~min})$ of balls that move in the same random motion without highlighting (block design: $1 \mathrm{~min} /$ period $\times 2$ periods $\times 3$ blocks). 


\section{Genotyping}

Samples of DNA will be extracted from whole blood or saliva collected in EDTA-tubes using DNeasy Blood \& Tissue Kit (catalog number 69506, Qiagen Inc., Valencia, CA, USA). Genomic DNA will be subjected to restriction fragment length polymorphism PCR to genotype each participant for $L M X 1 A$ at rs4657412 as described previously [68]. Specifically, approximately 3ng of genomic DNA will be amplified for LMX1A using the primer LMX-5': 5'-CTCGCCTCCAGGAATGGGTGTTGTA-3' and LMX-3': 5'-GCCACGAGGAACTTGTGAGAGGGTT-3', and under the following conditions: denaturation at $94 \mathrm{C}$ for $5 \mathrm{~min}$, followed by 30 cycles at $94{ }^{\circ} \mathrm{C}$ for $30 \mathrm{sec}$, annealing at $64{ }^{\circ} \mathrm{C}$ for $30 \mathrm{sec}$, and extending at $72{ }^{\circ} \mathrm{C}$ for 30 sec. $15 \mathrm{ul}$ of the amplification products will be digested by 2.5U of MslI (R0571s, New England Biolabs, Beverly, MA) for $2 \mathrm{~h}$ at $37^{\circ} \mathrm{C}$. The digested PCR products will be then analyzed on a $4 \%$ agarose gel and visualized using GelGreen ${ }^{\circ}$ Nucleic Acid Gel Stain (89139-144, Biotium, Hayward, CA).

\section{Cerebrospinal fluid cytokines/chemokines and dopamine/ dopamine-related metabolite measurements}

Lumbar punctures will be performed at baseline and 1 month after CWMT in participants who have agreed to spinal taps. The cerebrospinal fluid will be collected, aliquoted into $0.5 \mathrm{ml}$ portions, and swiftly frozen at $-80{ }^{\circ} \mathrm{C}$. Measurements for both ELISAs and monoamines will be run in batches.

\section{ELISA}

We will quantify fractalkine, IL-1 $\alpha$, MCP-1, IP-10, IL-8, and IL-4 using the RayBio ELISA kits (RayBiotech, Inc., Norcross, GA, USA). Since fractalkine concentration is relatively low even in normal serum and plasma, and may not be detected in the RayBio assay, we plan to use the $\mathrm{Hu}$ man Fractalkine ELISA kit (ADIPO Bioscience, Inc., Santa Clara, CA, USA), which is reportedly more sensitive [69].

\section{Cerebrospinal fluid dopamine and dopamine metabolite levels} These will be measured using HPLC assays [70] with electrochemical detectors and using principal component analysis precipitation to remove proteins and stabilize small molecule analytes. Internal standards will be used to measure monoamines and their metabolites, including norepinephrine, dopamine and its metabolites, 3,4-dihydroxyphenylacetic acid and homovanillic acid, as well as serotonin (5-hydroxytryptamine) and its metabolite, 5-hydroxyindole-3-acetic acid.

\section{Statistical analysis}

All analyses will be performed using SAS, using repeated-measures analysis of variance (ANOVA) as the primary model (co-varied for age and sex). The baseline (initial) values of all key variables will be tested for normality prior to analysis. Appropriate transformations (or non-parametric tests) will be used as necessary. The statistical significance will be determined using a modified Bonferroni procedure for multiple tests [71]. The procedure will have a type I error probability equal to 0.05 for independent tests.

Neurocognitive assessments will be tested using appropriately constructed contrasts within a $2 \times 2$ repeatedmeasures ANOVA model. HIV status (and HAND status for subgroup analyses) and training condition (adaptive versus fixed) will be across-subjects variables, and time (baseline, 1-month, 6-months) will be within-subject variables. Analyses will be co-varied for subject age, sex, and other co-variates as needed (e.g., depression scores). Subjects trained in both the adaptive and fixed training will have the training condition as a within-subject variable.

The fMRI time series will be analyzed using Statistical Parametric Mapping software (SPM8, Welcome Department of Cognitive Neurology, UK). After spatial normalization and smoothing, maps of brain activation and differential changes in activation (repeat - baseline) will be calculated for each subject and task, using a fixed-effects model with a block design. In a subsequent random-effects analysis, differences between groups on BOLD signal changes will be evaluated for each task ( $t$ tests or ANOVA). Statistical significance will be based on cluster-level significance at $P<0.05$ corrected for multiple comparisons (voxel-level threshold $P<0.05$, cluster size $>100$ voxels). Additionally, we will extract regional percentage BOLD-fMRI signals from cubic regions of interest $\left(0.729 \mathrm{~cm}^{3}\right)$ centered at cluster maxima, using a customized program written in MATLAB. The extracted data will be imported into SAS, where a repeatedmeasures ANOVA model will be run to confirm and further evaluate the statistical parametric mapping findings.

For the genetic study, we will first determine the Hardy-Weinberg equilibrium for both allelic and genotype frequencies of the $L X M 1 A$ gene in our cohort. To minimize the number of correlations, we will use repeated-measures ANOVA to select cognitive variables and extracted fMRI data that show changes from baseline to 6 months after CWMT (adaptive versus active control). We will assess the relationship of these variables with the LMX1A genotypes and with cerebrospinal fluid markers using ANCOVA. Repeated measure ANCOVAs and multivariate ANCOVAs will also be utilized.

\section{Dissemination plan}

At the completion of this trial, we plan to submit several manuscripts to peer-reviewed journals including;

1. 'Neural correlates of adaptive working memory training in HIV patients': this paper will report on 
the interim findings from the primary outcome measures, including improvements on working memory performance and neural efficiencies, 1 month and 6 months after the adaptive version of CWMT, to assess the gain and maintenance of working memory improvements after training. Some of the secondary contrast results, including scoring on the Behavior Rating Inventory of Executive Function-Adult Version and $L M X 1 A$ genotype effects, will also be reported. These findings may lead to a larger study to validate whether CWMT can be used as an adjunctive therapy for HAND.

2. 'Computerized working memory training in HIV patients: a double-blind active control study': this paper will be written at the completion of subject enrollments. We will compare the effects of adaptive versus fixed low level of CWMT on the primary outcome measures, at 1 month and 6 months after training compared with baseline assessments. This will provide further evidence of whether CWMT is effective for working memory and attention deficits in HIV patients.

3. This paper will also report on the findings after the double-blind active control study to evaluate the efficacy of CWMT on the secondary outcome measures, including scores on the the Center for Epidemiological Studies-Depression Scale, Revised, and the Symptom Checklist-90-revised, and ability to conduct activities of daily living (Independent Activity of Daily Living assessment and the Behavior Rating Inventory of Executive Function-Adult Version) before and after CWMT.

4. This paper will report on possible improvements in cerebrospinal fluid neuroinflammatory proteins (chemokines and cytokines) and neurochemicals (dopamine and serotonergic levels and their metabolites) after CWMT. Since only half of the participants might consent to the lumbar punctures, we may need to combine results from the adaptive training group and the fix-low-level training group to evaluate the training effects on these cerebrospinal fluid measurements.

We plan to submit our first manuscript on the interim findings before the end of the project in 2015, and the other three papers in 2016 or 2017. The findings will also be presented and discussed at international conferences and workshops, as well as at local symposia to our community healthcare providers.

\section{Discussion}

Cogmed Working Memory Training ${ }^{\oplus}$ may be a useful adjunctive treatment for HAND in HIV-positive patients who are receiving combined antiretroviral therapy. Since
CWMT is non-invasive and can be accessed from any computer via the internet, this safe intervention is easily accessible and costs less than typical pharmacological treatments. Furthermore, the proposed work may provide direct and immediate novel data on the long-term maintenance effect of adaptive working memory training, and insight into how the brain and the neural networks involved in working memory and attention may be modified by the training.

The proposed research has several innovative aspects. (1) We will evaluate a new, non-invasive approach to improve cognitive function in HIV-positive subjects. Except for a single recent report of a pilot study of 'internet-based cognitive stimulation' (using SmartBrain $\odot$ ) [72], the proposed intervention with CWMT is, to our knowledge, the first to evaluate whether working memory and other cognitive domains can be improved in HIV patients. (2) This will, to our knowledge, be the first study to assess neural plasticity of cognitive training in HIV patients. We will evaluate the neural correlates of the cognitive improvements associated with the intervention, using fMRI techniques. (3) We will genotype subjects to determine whether individuals with the TT(AA) alleles for the LXMI1A gene perform better at working memory training. This may pave the way for personalized treatments in the future. (4) Further insights will be derived from studying the relationships between neuroinflammation and brain function (correlations among neuropsychological test scores, working memory performance from the CWMT program, and cerebrospinal fluid cytokines or chemokines). Our approach will provide unique insights into how the brain changes after cognitive training. If successful, the study could lead to a larger intervention study to determine whether working memory training may prevent or improve behavioral and cognitive problems that affect HIV-infected patients. Training the brain might be analogous to physical exercise to prevent cardiovascular diseases, and lead to a new era of prevention for brain disorders.

\section{Expected findings \\ Gain in working memory performance and transfer of gain to 'near' or 'far' transfer tasks (Aim 1)}

HIV-positive subjects commonly have working memory deficits [3, 23-29, 41-43]. Since working memory is needed to maintain focus on tasks, deficits in working memory may negatively affect many other cognitive domains, and result in HAND. Prior studies of CWMT showed that the program enhanced performance not only on trained working memory tasks, but also on some non-trained visuospatial and non-trained complex reasoning tasks, including executive function [73]. Therefore, we aim to evaluate the efficacy of CWMT on cognitive performance in our subjects. 
We hypothesize that all subjects will show improved working memory after Cogmed $^{\circ}$ RM training (adaptive training > low fixed level 'active control' training), both at 1 month and at 6 months after cessation of training. In addition, not only will adaptive CWMT will lead to greater improvements than active control training on the trained tasks, but the gain will transfer to nontrained tasks that require similar working memory processes, including near-transfer tasks (e.g., digit span and spatial span) and far-transfer tasks (e.g., verbal learning, logical memory, short-term memory, and recognition memory). Lastly, we expect that the gain will be greater in subjects with normal cognition (regardless of HIV status) than in those with cognitive deficits (e.g., HAND or HAND-equivalent).

\section{BOLD-fMRI studies (Aim 2)}

BOLD-fMRI has been used to evaluate brain changes in HIV-positive patients for more than a decade. BOLDfMRI signals in these individuals are altered during tasks that require working memory $[74,75]$ and visual attention [74, 76]. A prior study showed that HIV patients had a lower working memory network capacity, which was further affected by other concurrent brain activities (e.g., louder acoustic noise proportionally decreased working memory activation); hence, they would be distracted more easily by other activities in their daily life [75]. Hence, we expect that subjects with normal cognition (higher working memory capacity) will show greater improvement than those with cognitive deficits.

BOLD-fMRI signals during working memory tasks were also greater in cognitively normal HIV-positive subjects compared with seronegative controls [77], as well as in HIV-positive subjects receiving antiretroviral medications compared with both HIV-negative and antiretroviral medication-naïve subjects and seronegative controls [6]. Greater BOLD-fMRI signals in HIV patients were predicted by higher levels of glial metabolites (myoinositol, total creatine, and choline) [78]. These findings suggest that ongoing increased neuroinflammation in HIV patients necessitates greater usage of the working memory network. Such neuroinflammation appeared to be ongoing despite stable antiretroviral treatments, since HIV-positive subjects showed increased BOLD-fMRI signals within the visual attention network in a one-year longitudinal followup study (suggesting decline efficiency), while matched seronegative controls showed decreased BOLD-fMRI signals (consistent with a test-retest practice effect) [79]. Therefore, this study will also explore how neuroinflammation as assessed by cerebrospinal fluid inflammatory markers is related to BOLD-fMRI signals before and after working memory training.

For this aim, we predict that all subjects will show improved BOLD signals with decreased activation, indicating greater neural efficiency, in brain networks associated with working memory ( $n$-back) and visual attention (ball tracking), at 1 month and 6 months after adaptive working memory training compared with baseline and relative to active control training. Also, brain activation will normalize in HIV-positive subjects, who will show smaller group differences compared with seronegative controls at 1 month and even smaller differences at 6 months after adaptive working memory training.

\section{Genotype effects (Aim 3)}

Since HIV patients have dopaminergic deficits, with decreased dopamine transporters $[18,19]$ and decreased cerebrospinal fluid dopamine and dopamine metabolites [62], genetic variations in genes related to dopamine metabolism, such as $L M X 1 A$ or catechol-O-methyltransferase, may modulate working memory training effects, BOLDfMRI results, and cerebrospinal fluid monoamine levels [55]. For instance, while HIV-positive subjects with the Met/Met alleles at the catechol-O-methyltransferase Val58Met gene (a gene involved in the degradation of released dopamine) perform better on executive function [80], healthy individuals with the TT(AA) alleles at the $L M X 1 A$ rs4657412 benefit more from working memory training than those individuals with the $\mathrm{C}(\mathrm{G})$-carrier [55]. Therefore, we predict that polymorphism of the $L M X 1 A$ gene will differentially affect cognitive improvements among HIV-positive individuals. Specifically, consistent with a prior report, we expect that, regardless of HIV serostatus, subjects with the TT(AA)-alleles at the LMX1A-rs4657412 will perform better on verbal working memory tasks and have greater training-related gains in verbal working memory than those carrying the $\mathrm{C}(\mathrm{G})$-allele after CWMT [55], especially in subjects with normal cognitive function. We also expect that TT(AA)-carriers will show greater improved neural efficiencies, i.e., greater decreases in BOLDfMRI, than TC(AG) or CC(GG) carriers.

\section{Cerebrospinal fluid neuroinflammatory markers and monoamine metabolites (exploratory aim)}

Numerous studies indicate that ongoing aberrant neuroinflammation in HIV-infected individuals might contribute to brain injury associated with HAND [4, 81-83]. In prior studies, cerebrospinal fluid level of MCP-1 correlated with brain metabolites [84], and the three cerebrospinal fluid chemokines (MCP-1, IP-10, and IL-8) had the strongest correlations with cerebral metabolite patterns [82]. We will measure pro-inflammatory cytokines (fractalkine, INF- $\alpha 2$, and IL- $1 \alpha$ ), chemo-attractants (MCP-1, IP-10, and IL-8) and anti-inflammatory cytokines (IL-4) in the cerebrospinal fluid of our study participants. We hypothesize that, at baseline, levels of pro-inflammatory cytokines (fractalkine, INF- $\alpha 2$, and 
IL- $1 \alpha)$ and chemo-attractants (MCP-1, IP-10, and IL-8) will be higher, while the anti-inflammatory cytokine (IL-4) will be lower in HIV-positive subjects, especially in those with HAND, compared with seronegative controls. These markers will correlate with cognitive performance and BOLD-fMRI signals at baseline more so than at 6 months after training.

Furthermore, many symptoms of HAND are consistent with mild Parkinson's disease; correspondingly, HIV patients show dopaminergic terminal deficits, with decreased dopamine transporters [18, 19], and decreased cerebrospinal fluid dopamine and dopamine metabolites [62]. Dopamine transporters also correlated with deactivation in the default mode network on visual attention task [85]. Furthermore, changes in cortical dopamine D1 receptor binding observed by positron emission tomography were associated with improvement from CWMT [86]. Therefore, we expect cerebrospinal fluid monoamine and metabolite levels to be lower in HIV than in seronegative subjects at baseline, but levels may increase after CWMT. We also expect that these levels will correlate with cognitive function and BOLD-fMRI signals both before and after CWMT.

\section{Additional considerations and future directions}

1. Based on our pilot study, individuals with HAND had the highest dropout rate, probably owing to frustrations or lack of motivation. Therefore, we will spend more time to train these participants in our laboratory initially and coach them during the early phase of the training (contacting them three or more times per week).

2. We will also ensure that each participant will have a computer and high-speed internet access (e.g., by providing internet cards and inexpensive computers, or by training them in our laboratory, which we have done successfully during the pilot study). The training program, CWMT, can be accessed via internet from any computer.

3. Furthermore, while typical medication trials terminate clinical contact after the medication phase, we plan to follow the subjects for 6 months after CWMT; this allows us to collect novel data on the long-term maintenance effect of adaptive working memory training and determine whether there are any carry-over (positive or negative) effects of the experimental condition.

4. Lastly, we will collect information regarding physical exercise and sleep patterns, which could either enhance or interfere with both baseline cognitive functioning and their training outcomes [87-89]. As discussed, cognitive training or stimulation might be analogous to physical exercise to prevent cardiovascular diseases, and lead to prevention or delay development of dementia both in seronegative and HIV-positive subjects.
The proposed research has significant public health impact since HAND is an increasing problem with significant impact on the lives of afflicted patients and a growing financial burden to society. The findings from this protocol may provide foundational information necessary for the development of a potential adjunctive non-pharmacological treatment for HAND.

HIV-positive patients with HAND experience difficulties in activities of daily living and negative emotional well-being. Cognitive deficits and impairment of working memory are often overlooked, but may in fact be 'treatable'. The data reviewed clearly demonstrate the urgency of this emerging problem, especially as the HIV-infected population continues to grow and age. Therefore, our proposed research has high significance in that the findings may lead to an intervention that might improve the cognitive function of HIV-infected individuals with HAND, and possibly delay or prevent the development of HAND in others.

\section{Trial status}

The trial started in September 2012, and is currently enrolling participants.

\section{Abbreviations \\ ANCOVA: analysis of covariance; ANOVA: (analysis of variance); BOLD: blood- oxygenation level-dependent; CWMT: Cogmed Working Memory Training ${ }^{\circledR}$; ELISA: enzyme-linked immunosorbent assay; fMRI: functional magnetic resonance imaging; GRAPPA: generalized autocalibrating partially parallel acquisitions; HAND: HIV-associated neurocognitive disorders; HIV: human immunodeficiency virus; HPLC: high performance liquid chromatography; IL: interleukin; LMX1A: LIM homeobox transcription factor 1, alpha; MRI: magnetic resonance imaging; PCR: polymerase chain reaction; TE: echo time; TI: inversion time; TR: repetition time.}

\section{Competing interests}

The authors declare that they have no competing interests.

\section{Authors' contributions}

LC and TE: conception and design, data collection and analysis, manuscript writing, and final approval of the manuscript. GL: conception and design of the cognitive battery, data interpretation, manuscript writing, critical revision, and final approval of the manuscript. JS: conception and design, critical revision and final approval of the manuscript. EM: conception and design of the cognitive battery, critical revision and approval of the final manuscript. VD: conception and design, preparation and final approval of the manuscript. All authors read and approved the final manuscript.

\section{Acknowledgements}

Grant support from NIH: 1R01-DA035659; 2K24-DA16170; G12 MD007601. We are grateful to our research participants and the referral healthcare providers from our community, and the personnel at the Life Foundation. We also appreciate the work from our clinical and technical research staff members who were involved in the data collection for this study.

\section{Author details}

${ }^{1}$ Department of Medicine, John A. Burns School of Medicine, The Queen's Medical Center, University of Hawaii at Manoa, 1356 Lusitana Street, 7th Floor UH Tower, Honolulu, HI, USA. ²Department of Pediatrics, Sørlandet Hospital, Arendal, Norway. ${ }^{3}$ Department of Laboratory Medicine, Children's and Women's Health, Norwegian University of Science and Technology, Trondheim, Norway. ${ }^{4}$ UCLA Psychiatry and Biobehavioral Sciences, Los Angeles, CA, USA. 
Received: 22 November 2015 Accepted: 7 January 2016

\section{Published online: 02 February 2016}

\section{References}

1. Heaton RK, Franklin DR, Ellis RJ, McCutchan JA, Letendre SL, Leblanc S, et al. HIV-associated neurocognitive disorders before and during the era of combination antiretroviral therapy: differences in rates, nature, and predictors. J Neurovirol. 2011;17(1):3-16.

2. McArthur JC, Steiner J, Sacktor N, Nath A. Human immunodeficiency virus-associated neurocognitive disorders: mind the gap. Ann Neurol. 2010;67(6):699-714.

3. Halkitis P, Palamar J, Mukherjee P. Analysis of HIV medication adherence in relation to person and treatment characteristics using hierarchical linear modeling. AIDS Patient Care STDS. 2008;22(4):323-35.

4. Hinkin CH, Barclay TR, Castellon SA, Levine AJ, Durvasula RS, Marion SD, et al. Drug use and medication adherence among HIV-1 infected individuals. AIDS Behav. 2007;11(2):185-94.

5. Simioni S, Cavassini M, Annoni JM, Rimbault Abraham A, Bourquin I, Schiffer $\checkmark$, et al. Cognitive dysfunction in HIV patients despite long-standing suppression of viremia. Aids. 2010;24(9):1243-50.

6. Chang L, Yakupov R, Nakama H, Stokes B, Ernst T. Antiretroviral treatment is associated with increased attentional load-dependent brain activation in HIV patients. J Neuroimmune Pharmacol. 2008;3(2):95-104. doi:10.1007/ s11481-007-9092-0.

7. Ernst T, Jiang CS, Nakama H, Buchthal S, Chang L. Lower brain glutamate is associated with cognitive deficits in HIV patients: a new mechanism for HIVassociated neurocognitive disorder. J Magn Reson Imaging. 2010;32(5): 1045-53. doi:10.1002/jmri.22366.

8. Vivithanaporn P, Asahchop EL, Acharjee S, Baker GB, Power C. HIV protease inhibitors disrupt astrocytic glutamate transporter function and neurobehavioral performance. Aids. 2015. doi:10.1097/QAD.00000000 00000955.

9. Sacktor N, Miyahara S, Deng L, Evans S, Schifitto G, Cohen BA, et al. Minocycline treatment for HIV-associated cognitive impairment: results from a randomized trial. Neurology. 2011;77(12):1135-42.

10. Eggert D, Dash PK, Gorantla S, Dou H, Schifitto G, Maggirwar SB, et al. Neuroprotective activities of CEP-1347 in models of neuroAIDS. J Immunol. 2010;184(2):746-56.

11. Zhao Y, Navia BA, Marra CM, Singer EJ, Chang L, Berger J, et al. Memantine for AIDS dementia complex: open-label report of ACTG 301. HIV Clin Trials. 2010;11(1):59-67.

12. Schifitto G, Zhong J, Gill D, Peterson DR, Gaugh MD, Zhu T, et al. Lithium therapy for human immunodeficiency virus type 1-associated neurocognitive impairment. J Neurovirol. 2009;15(2):176-86.

13. Heseltine PN, Goodkin K, Atkinson JH, Vitiello B, Rochon J, Heaton RK, et al. Randomized double-blind placebo-controlled trial of peptide T for HIVassociated cognitive impairment. Arch Neurol. 1998;55(1):41-51.

14. Sacktor N, Schifitto G, McDermott MP, Marder K, McArthur JC, Kieburtz K. Transdermal selegiline in HIV-associated cognitive impairment: pilot, placebo-controlled study. Neurology. 2000;54(1):233-5.

15. Schifitto G, Yiannoutsos CT, Ernst T, Navia BA, Nath A, Sacktor N, et al. Selegiline and oxidative stress in HIV-associated cognitive impairment. Neurology. 2009;73(23):1975-81.

16. Schifitto G, Zhang J, Evans SR, Sacktor N, Simpson D, Millar LL, et al. A multicenter trial of selegiline transdermal system for HIV-associated cognitive impairment. Neurology. 2007;69(13):1314-21.

17. Chang L, Jiang C, Cunningham E, Buchthal S, Douet V, Andres M, et al. Effects of APOE epsilon4, age, and HIV on glial metabolites and cognitive deficits. Neurology. 2014;82(24):2213-22. doi:10.1212/WNL.0000000000000526.

18. Chang L, Wang GJ, Volkow ND, Ernst T, Telang F, Logan J, et al. Decreased brain dopamine transporters are related to cognitive deficits in HIV patients with or without cocaine abuse. Neurolmage. 2008;42(2):869-78. doi:10.1016/ j.neuroimage.2008.05.011.

19. Wang GJ, Chang L, Volkow ND, Telang F, Logan J, Ernst T, et al. Decreased brain dopaminergic transporters in HIV-associated dementia patients. Brain. 2004;127(Pt 11):2452-8. doi:10.1093/brain/awh269.

20. Yeung $H$, Krentz HB, Gill MJ, Power C. Neuropsychiatric disorders in HIV infection: impact of diagnosis on economic costs of care. Aids. 2006;20(16):2005-9.

21. Cysique LA, Bain MP, Brew BJ, Murray JM. The burden of HIV-associated neurocognitive impairment in Australia and its estimates for the future. Sex Health. 2011;8(4):541-50. doi:10.1071/SH11003.
22. Wimo A, Winblad B. Pharmacoeconomics of mild cognitive impairment. Acta Neurol Scand Suppl. 2003;179:94-9.

23. Bartok JA, Martin EM, Pitrak DL, Novak RM, Pursell KJ, Mullane KM, et al. Working memory deficits in HIV-seropositive drug users. J Int Neuropsychol Soc. 1997;3(5):451-6.

24. Stout JC, Salmon DP, Butters N, Taylor M, Peavy G, Heindel WC, et al. Decline in working memory associated with HIV infection. Psychol Med. 1995;25(6):1221-32.

25. Farinpour R, Martin EM, Seidenberg M, Pitrak DL, Pursell KJ, Mullane KM, et al. Verbal working memory in HIV-seropositive drug users. J Int Neuropsychol Soc. 2000;6(5):548-55.

26. Martin EM, Sullivan TS, Reed RA, Fletcher TA, Pitrak DL, Weddington W, et al. Auditory working memory in HIV-1 infection. J Int Neuropsychol Soc. 2001;7(1):20-6.

27. Hinkin CH, Hardy DJ, Mason Kl, Castellon SA, Lam MN, Stefaniak M, et al. Verbal and spatial working memory performance among HIV-infected adults. J Int Neuropsychol Soc. 2002;8(4):532-8.

28. Woods SP, Moore DJ, Weber E, Grant I. Cognitive neuropsychology of HIVassociated neurocognitive disorders. Neuropsychol Rev. 2009;19(2):152-68. doi:10.1007/s11065-009-9102-5.

29. Chang L, Ernst T, Witt M, Ames N, Walot I, Jovicich J, et al. Persistent brain abnormalities in antiretroviral-naïve HIV patients three-months after HAART. Antivir Ther. 2003;8:17-26.

30. Heaton RK, Marcotte TD, Mindt MR, Sadek J, Moore DJ, Bentley H, et al. The impact of HIV-associated neuropsychological impairment on everyday functioning. J Int Neuropsychol Soc. 2004;10(3):317-31.

31. Bassel C, Rourke SB, Halman MH, Smith ML. Working memory performance predicts subjective cognitive complaints in HIV infection. Neuropsychology. 2002;16(3):400-10.

32. Selnes OA. Neurocognitive aspects of medication adherence in HIV infection. J Acquir Immune Defic Syndr. 2002;31 Suppl 3:S132-5.

33. Thames AD, Kim MS, Becker BW, Foley JM, Hines LJ, Singer EJ, et al. Medication and finance management among HIV-infected adults: the impact of age and cognition. J Clin Exp Neuropsychol. 2011;33(2):200-9. doi:10.1080/13803395.2010.499357.

34. Klingberg T, Forssberg $\mathrm{H}$, Westerberg $\mathrm{H}$. Training of working memory in children with ADHD. J Clin Exp Neuropsychol. 2002;24(6):781-91. doi:10.1076/jcen.24.6.781.8395.

35. Klingberg T, Fernell E, Olesen PJ, Johnson M, Gustafsson P, Dahlstrom K, et al. Computerized training of working memory in children with ADHD - a randomized, controlled trial. J Am Acad Child Adolesc Psychiatry. 2005;44(2):177-86. doi:10.1097/00004583-200502000-00010.

36. Johansson B, Tornmalm M. Working memory training for patients with acquired brain injury: effects in daily life. Scand J Occup Ther. 2011;19(2):176-83.

37. Westerberg H, Jacobaeus H, Hirvikoski T, Clevberger P, Ostensson ML, Bartfai A, et al. Computerized working memory training after stroke - a pilot study. Brain Inj. 2007;21(1):21-9. doi:10.1080/02699050601148726.

38. Lohaugen GC, Antonsen I, Haberg A, Gramstad A, Vik T, Brubakk AM, et al. Computerized working memory training improves function in adolescents born at extremely low birth weight. J Pediatr. 2011;158(4):555-61. e4.

39. Kronenberger WG, Pisoni DB, Henning SC, Colson BG, Hazzard LM. Working memory training for children with cochlear implants: a pilot study. J Speech Lang Hear Res. 2011;54(4):1182-96.

40. Brehmer $Y$, Westerberg $H$, Backman L. Working-memory training in younger and older adults: training gains, transfer, and maintenance. Front Hum Neurosci. 2012;6:63. doi:10.3389/fnhum.2012.00063.

41. Bell J. The neuropathology of adult HIV infection. Rev Neurol. 1998;154(12):816-29.

42. Law WA, Martin A, Mapou RL, Roller TL, Salazar AM, Temoshok LR, et al. Working memory in individuals with HIV infection. J Clin Exp Neuropsychol. 1994;16(2):173-82.

43. York MK, Franks JJ, Henry RR, Hamilton WJ. Verbal working memory storage and processing deficits in HIV-1 asymptomatic and symptomatic individuals. Psychol Med. 2001;31(7):1279-91.

44. Tomasi D, Ernst T, Caparelli EC, Chang L. Practice-induced changes of brain function during visual attention: a parametric fMRI study at 4 Tesla. Neurolmage. 2004;23(4):1414-21. doi:10.1016/j.neuroimage.2004.07.065.

45. van Turennout M, Ellmore T, Martin A. Long-lasting cortical plasticity in the object naming system. Nat Neurosci. 2000;3(12):1329-34. doi:10.1038/81873.

46. Grafton ST, Hazeltine E, Ivry R. Functional mapping of sequence learning in normal humans. J Cogn Neurosci. 1995;7:497-510. 
47. Karni A, Meyer G, Jezzard P, Adams MM, Turner R, Ungerleider LG. Functional MRI evidence for adult motor cortex plasticity during motor skill learning. Nature. 1995;377:155-8.

48. Buchel C, Coull JT, Friston KJ. The predictive value of changes in effective connectivity for human learning. Science. 1999;283(5407):1538-41.

49. Garavan H, Kelley D, Rosen A, Rao SM, Stein EA. Practice-related functional activation changes in a working memory task. Microsc Res Tech. 2000;51:54-63.

50. Jansma JM, Ramsey NF, Slagter HA, Kahn RS. Functional anatomical correlates of controlled and automatic processing. J Cogn Neurosci. 2001;13(6):730-43.

51. Olesen PJ, Westerberg H, Klingberg T. Increased prefrontal and parietal activity after training of working memory. Nat Neurosci. 2004;7(1):75-9. doi:10.1038/nn1165.

52. Westerberg $\mathrm{H}$, Klingberg $\mathrm{T}$. Changes in cortical activity after training of working memory - a single-subject analysis. Physiol Behav. 2007:92(1-2):186-92.

53. Brehmer $Y$, Rieckmann A, Bellander $M$, Westerberg $H$, Fischer $H$, Backman $L$. Neural correlates of training-related working-memory gains in old age. Neurolmage. 2011;58(4):1110-20. doi:10.1016/j.neuroimage.2011.06.079.

54. Dahlin E, Neely AS, Larsson A, Backman L, Nyberg L. Transfer of learning after updating training mediated by the striatum. Science. 2008;320(5882): 1510-2. doi:10.1126/science.1155466.

55. Bellander M, Brehmer $Y$, Westerberg $H$, Karlsson S, Furth D, Bergman O, et al. Preliminary evidence that allelic variation in the LMXIA gene influences training-related working memory improvement. Neuropsychologia. 2011;49(7): 1938-42. doi:10.1016/j.neuropsychologia.2011.03.021.

56. Bellander M, Backman L, Liu T, Schjeide BM, Bertram L, Schmiedek F, et al. Lower baseline performance but greater plasticity of working memory for carriers of the val allele of the COMT Val(1)(5)(8)Met polymorphism. Neuropsychology. 2015;29(2):247-54. doi:10.1037/neu0000088.

57. Friling S, Andersson E, Thompson LH, Jonsson ME, Hebsgaard JB, Nanou E, et al. Efficient production of mesencephalic dopamine neurons by $L m \times 1 a$ expression in embryonic stem cells. Proc Natl Acad Sci USA. 2009;106(18): 7613-8. doi:10.1073/pnas.0902396106.

58. Nakatani T, Kumai M, Mizuhara E, Minaki Y, Ono Y. Lmx1a and Lmx1b cooperate with Foxa2 to coordinate the specification of dopaminergic neurons and control of floor plate cell differentiation in the developing mesencephalon. Dev Biol. 2010;339(1):101-13. doi:10.1016/j.ydbio. 2009.12.017

59. Smidt MP, Burbach JP. How to make a mesodiencephalic dopaminergic neuron. Nat Rev Neurosci. 2007:8(1):21-32. doi:10.1038/nrn2039.

60. Bergman O, Hakansson A, Westberg L, Belin AC, Sydow O, Olson L, et al. Do polymorphisms in transcription factors $\angle M X 1 A$ and $L M X 1 B$ influence the risk for Parkinson's disease? J Neural Transm. 2009;116(3):333-8. doi:10.1007/ s00702-009-0187-z.

61. Bergman O, Westberg L, Nilsson LG, Adolfsson R, Eriksson E. Preliminary evidence that polymorphisms in dopamine-related transcription factors LMXIA, LMX1B and PITX3 are associated with schizophrenia. Prog Neuropsychopharmacol Biol Psychiatry. 2010;34(6):1094-7. doi:10.1016/j. pnpbp.2010.05.032.

62. Berger JR, Kumar M, Kumar A, Fernandez J, Levin B. Cerebrospinal fluid dopamine in HIV-1 infection. Acquir Immunodef Syndr. 1994;8(1):67-71.

63. Antinori A, Arendt G, Becker JT, Brew BJ, Byrd DA, Cherner M, et al. Updated research nosology for HIV-associated neurocognitive disorders. Neurology. 2007;69(18):1789-99.

64. Lohaugen GC, Antonsen I, Haberg A, Gramstad A, Vik T, Brubakk AM, et al. Computerized working memory training improves function in adolescents born at extremely low birth weight. J Pediatr. 2010;158(4):555-61. e4.

65. Spreen O, Strauss E. A compendium of neuropsychological tests: administration, norms and commentary. New York: Oxford University Press; 1998.

66. Pylyshyn ZW, Storm RW. Tracking multiple independent targets: evidence for a parallel tracking mechanism. Spat Vis. 1988;3(3):179-97.

67. Jovicich J, Peters RJ, Koch C, Braun J, Chang L, Ernst T. Brain areas specific for attentional load in a motion tracking task. J Cogn Neurosci. 2001;13:1048-58.

68. Flak MM, Hernes SS, Skranes J, Lohaugen GC. The Memory Aid study: protocol for a randomized controlled clinical trial evaluating the effect of computerbased working memory training in elderly patients with mild cognitive impairment (MCI). Trials. 2014;15:156. doi:10.1186/1745-6215-15-156.
69. Clark AK, Staniland AA, Malcangio M. Fractalkine/CX3CR1 signalling in chronic pain and inflammation. Curr Pharm Biotechnol. 2011;12(10): 1707-14.

70. Yang $L$, Beal MF. Determination of neurotransmitter levels in models of Parkinson's disease by HPLC-ECD. Methods Mol Biol. 2011;793:401-15.

71. Simes RJ. An improved Bonferroni procedure for multiple tests of significance. Biometrika. 1986;73(3):751-4.

72. Becker JT, Dew MA, Aizenstein HJ, Lopez OL, Morrow L, Saxton J, et al. A pilot study of the effects of internet-based cognitive stimulation on neuropsychological function in HIV disease. Disabil Rehabil. 2012;34(21):1848-52.

73. Diamond A, Lee K. Interventions shown to aid executive function development in children 4 to 12 years old. Science. 2011;333(6045):959-64. doi:10.1126/science.1204529.

74. Chang L, Speck O, Miller E, Braun A, Jovicich J, Koch C, et al. Neural correlates of attention and working memory deficits in HIV patients. Neurology. 2001;57:1001-7.

75. Tomasi D, Chang L, de Castro CE, Telang F, Ernst T. The human immunodeficiency virus reduces network capacity: acoustic noise effect. Ann Neurol. 2006;59(2):419-23. doi:10.1002/ana.20766.

76. Chang L, Tomasi D, Yakupov R, Lozar C, Arnold S, Caparelli E, et al. Adaptation of the attention network in human immunodeficiency virus brain injury. Ann Neurol. 2004;56(2):259-72.

77. Ernst T, Chang L, Jovicich J, Ames N, Arnold S. Abnormal brain activation on functional MRI in cognitively asymptomatic HIV patients. Neurology. 2002;59(9):1343-9.

78. Ernst T, Chang L, Arnold S. increased glial markers predict increased working memory network activation in HIV patients. Neurolmage. 2003;19(4):1686-93.

79. Ernst T, Yakupov R, Nakama H, Crocket G, Cole M, Watters M, et al. Declined neural efficiency in cognitively stable human immunodeficiency virus patients. Ann Neurol. 2009;65(3):316-25.

80. Bousman CA, Cherner M, Atkinson JH, Heaton RK, Grant I, Everall IP, et al. COMT Val158Met polymorphism, executive dysfunction, and sexual risk behavior in the context of HIV infection and methamphetamine dependence. Interdiscip Perspect Infect Dis. 2010;2010:678648.

81. Lindl KA, Marks DR, Kolson DL, Jordan-Sciutto KL. HIV-associated neurocognitive disorder: pathogenesis and therapeutic opportunities. J Neuroimmune Pharmacol. 2010;5(3):294-309.

82. Letendre SL, Zheng JC, Kaul M, Yiannoutsos CT, Ellis RJ, Taylor MJ, et al. Chemokines in cerebrospinal fluid correlate with cerebral metabolite patterns in HIV-infected individuals. J Neurovirol. 2011;17(1):63-9.

83. Chang L, Ernst T, Witt M, Ames N, Jocivich J, Speck O, et al. Relationships among cerebral metabolites, cognitive function and viral loads in antiretroviral-naïve HIV patients. Neurolmage. 2002;17(3):1638-48.

84. Chang L, Ernst T, St Hillaire C, Conant K. Antiretroviral treatment alters relationship between MCP-1 and neurometabolites in HIV patients. Antivir Ther. 2004;9(3):431-40

85. Tomasi D, Volkow ND, Wang R, Telang F, Wang GJ, Chang L, et al. Dopamine transporters in striatum correlate with deactivation in the default mode network during visuospatial attention. PLoS One. 2009;4(6):e6102. doi: 10.1371/journal.pone.0006102.

86. McNab F, Varrone A, Farde L, Jucaite A, Bystritsky P, Forssberg $H$, et al. Changes in cortical dopamine D1 receptor binding associated with cognitive training. Science. 2009:323(5915):800-2. doi:10.1126/science.1166102.

87. Denkinger MD, Nikolaus T, Denkinger C, Lukas A. Physical activity for the prevention of cognitive decline: current evidence from observational and controlled studies. Z Gerontol Geriatr. 2012;45(1):11-6.

88. Hindin SB, Zelinski EM. Extended practice and aerobic exercise interventions benefit untrained cognitive outcomes in older adults: a meta-analysis. J Am Geriatr Soc. 2012;60(1):136-41.

89. Drummond SP, Anderson DE, Straus LD, Vogel EK, Perez VB. The effects of two types of sleep deprivation on visual working memory capacity and filtering efficiency. PLoS One. 2012;7(4):e35653.

90. Hollingshead A. Four Factor Index of Social Status. New Haven, CT: Yale University; 1975.

91. Eaton WW, Smith C, Ybarra M, Muntaner C, Tien A. Center for Epidemiologic Studies Depression Scale: Review and Revision (CESD and CESD-R). In: Maruish ME, editor. The use of psychological testing for treatment planning and outcomes assessment. Mahwah, NJ: Lawrence Erlbaum; 2004. p. 363-77. 
92. Lazowski L, Miller F, Boye M, Miller G. Efficacy of the Substance Abuse Subtle Screening Inventory-3 (SASSI-3) in identifying substance dependence disorders in clinical settings. J Pers Assess. 1998;71(1):114-28.

93. Lawton MP, Brody EM. Assessment of older people: self-maintaining and instrumental activities of daily living. Gerontologist. 1969;9(3):179-86.

94. Buysse DJ. Reynolds 3rd CF, Monk TH, Berman SR, Kupfer DJ. The Pittsburgh Sleep Quality Index: a new instrument for psychiatric practice and research. Psychiatry Res. 1989;28(2):193-213.

95. Johns MW. A new method for measuring daytime sleepiness: the Epworth sleepiness scale. Sleep. 1991;14(6):540-5.

96. Wu AW, Revicki DA, Jacobson D, Malitz FE. Evidence for reliability, validity and usefulness of the Medical Outcomes Study HIV Health Survey (MOSHIV). Qual Life Res. 1997;6(6):481-93.

97. Group WHOsQoL. Development of the World Health Organization Quality of Life Instrument (WHOQOL). Measuring quality of life. Geneva: World Health Organization; 1992.

\section{Submit your next manuscript to BioMed Central} and we will help you at every step:

- We accept pre-submission inquiries

- Our selector tool helps you to find the most relevant journal

- We provide round the clock customer support

- Convenient online submission

- Thorough peer review

- Inclusion in PubMed and all major indexing services

- Maximum visibility for your research

Submit your manuscript at www.biomedcentral.com/submit 